\title{
In Vivo Assessment of the Impact of Regional Intracranial Atherosclerotic Lesions on Brain Arterial 3D Hemodynamics
}

\author{
(D) C. Wu, (D) S. Schnell, (D) P. Vakil, DA.R. Honarmand, (DS.A. Ansari, (D). Carr, DM. Markl, and DS. Prabhakaran
}

\begin{abstract}
BACKGROUND AND PURPOSE: Intracranial atherosclerosis induces hemodynamic disturbance, which is not well-characterized, particularly in cerebral flow redistribution. We aimed to characterize the impact of regional stenotic lesions on intracranial hemodynamics by using 4D flow MR imaging.
\end{abstract}

\begin{abstract}
MATERIALS AND METHODS: 4D flow MR imaging was performed in 22 symptomatic patients (mean age, $68.4 \pm 14.2$ years) with intracranial stenosis (ICA, $n=7$; MCA, $n=9$; basilar artery, $n=6$ ) and 10 age-appropriate healthy volunteers (mean age, $60.7 \pm 8.1$ years). 3D blood flow patterns were visualized by using time-integrated pathlines. Blood flow and peak velocity asymmetry indices were compared between patients and healthy volunteers in 4 prespecified arteries: ICAs, MCAs, and anterior/posterior cerebral arteries.

RESULTS: 3D blood flow pathlines demonstrated flow redistribution across cerebral arteries in patients with unilateral intracranial stenosis. For patients with ICA stenosis compared with healthy volunteers, significantly lower flow and peak velocities were identified in the ipsilateral ICA $(P=.001$ and $P=.001)$ and MCA $(P<.001$ and $P=.001)$, but higher flow, in the ipsilateral $P C A(P<.001)$. For patients with MCA stenosis, significantly lower flow and peak velocities were observed in the ipsilateral ICA $(P=.009$ and $P=.045)$ and MCA $(P<.001$ and $P=.005)$, but significantly higher flow was found in the ipsilateral posterior cerebral artery $(P=.014)$ and anterior cerebral artery $(P=$ .006). The asymmetry indices were not significantly different between patients with basilar artery stenosis and the healthy volunteers.
\end{abstract}

CONCLUSIONS: Regional intracranial atherosclerotic lesions not only alter distal arterial flow but also significantly affect ipsilateral collateral arterial hemodynamics.

ABBREVIATIONS: $\mathrm{ACA}=$ anterior cerebral artery; $\mathrm{AI}-\mathrm{F}=$ flow rate asymmetry index; $\mathrm{Al}-\mathrm{V}=$ peak velocity asymmetry index; $\mathrm{BA}=$ basilar artery; ICAD = intracranial atherosclerotic disease; PCA = posterior cerebral artery; PC-MRA = phase-contrast MR angiogram; VENC = velocity encoding

ntracranial atherosclerotic disease (ICAD) is characterized by narrowing and blockage of the major intracranial arteries due to accumulation of atherosclerotic plaques within the vessel wall. It represents one of the most common causes of ischemic stroke worldwide, with higher occurrence rates in Asians, Hispanics, and blacks than in whites. ${ }^{1}$

Received June 20, 2016; accepted after revision October 26.

From the Department of Biomedical Engineering (C.W., M.M.), McCormick School of Engineering, Northwestern University, Chicago, Illinois; Departments of Radiology (C.W., S.S., P.V., A.R.H., S.A.A., J.C., M.M.), Neurological Surgery (S.A.A.), and Neurology (S.P.), Feinberg School of Medicine, Northwestern University, Chicago, Illinois; and Philips Healthcare (C.W.), Gainesville, Florida.

This work was supported by American Heart Association Predoctoral Fellowship 14PRE18370014 and American Heart Association Scientist Development Grant 16SDG30420005

Please address correspondence to Can Wu, PhD, Department of Radiology, Northwestern University, 737 N Michigan Ave, Suite 1600, Chicago, IL 60611; e-mail: canwu2016@u.northwestern.edu

三 Indicates article with supplemental on-line tables.

http://dx.doi.org/10.3174/ajnr.A5051
Patients with symptomatic ICAD have a high risk of stroke recurrence, particularly those with high-grade (70\%-99\%) stenosis. ${ }^{2}$ Currently, aggressive medical management is recommended for the treatment of ICAD. However, approximately $12 \%$ of patients with ICAD experience a recurrent stroke within the first year. $^{3}$ Therefore, careful risk stratification and monitoring of ICAD are paramount. In particular, hemodynamic failure may impart a high risk in a subset of patients with ICAD. Local hemodynamic alterations secondary to ICAD, particularly in the locations proximal and distal to the stenosis, may be useful markers of recurrent stroke risk. ${ }^{4,5}$ Because DSA is invasive, noninvasive alternatives such as sonography and 2D phase-contrast MR imaging have been used to measure hemodynamic changes in patients with ICAD, classify stenosis severity, predict risk of recurrent stroke, and detect in-stent restenosis after stent placement. ${ }^{6-9}$ However, these techniques may be limited by low reproducibility, an inadequate insonation window, or insufficient anatomic coverage. In addition, the impact of atherosclerotic lesions on the hemodynamics in other vascular territories and the redistribution 
of cerebral blood flow through circle of Willis collaterals are not well-characterized. Furthermore, a 3D characterization of the stenosis-induced hemodynamic changes across the entire cerebral vasculature and a comparison of the hemodynamics between patients with ICAD and age-controlled healthy volunteers have not been previously reported, to our knowledge.

$4 \mathrm{D}$ flow MR imaging (ie, time-resolved 3D phase-contrast MR imaging with 3-directional velocity-encoding) provides reliable flow measurements consistent with 2D phase-contrast MR imaging and offers additional benefits, including retrospective flow quantification at any vessel location within the imaging volume and 3D blood flow visualization of the entire vasculature. ${ }^{10-12}$ Recently, 4D flow MR imaging has attracted increasing interest in the assessment of intracranial hemodynamics in patients with cerebrovascular diseases, such as intracranial aneurysms, vein of Galen malformation, and cerebral arteriovenous malformation. ${ }^{13-17}$

The purpose of this study was to evaluate the impact of regional intracranial atherosclerotic lesions on cerebral artery hemodynamics in comparison with healthy volunteers by using $4 \mathrm{D}$ flow MR imaging.

\section{MATERIALS AND METHODS \\ Study Subjects}

Between 2012 and 2014, clinical records of symptomatic patients with ICAD who had undergone $4 \mathrm{D}$ flow MR imaging were retrospectively reviewed $(n=26)$. The study included only patients with moderate $(50 \%-70 \%)$ to severe $(>70 \%)$ symptomatic intracranial stenosis. DSA, the criterion standard for stenosis measurement, is associated with a small but noticeable risk of complications; moreover, in the absence of an endovascular intervention, it is unreasonable to mandate its use. Alternatively, CTA has excellent diagnostic accuracy with a sensitivity and specificity of $>97 \%$ compared with DSA. ${ }^{18}$ TOF-MRA has been demonstrated to be a reliable tool for assessing intracranial artery stenosis, ${ }^{19}$ but contrast-enhanced MRA was superior to TOF-MRA for the detection of ICA stenosis. ${ }^{20}$ In our study, stenosis severity was evaluated on the basis of clinically available CTA or a combination of TOFMRA and contrast-enhanced MRA with a circle of Willis FOV. Two patients with near-occlusion stenosis were excluded because flow analysis was not possible due to slow flow, and 2 additional patients with bilateral stenosis were also excluded. Twenty-two patients (mean age, $68.4 \pm 14.2$ years; 10 women) and 10 ageappropriate healthy volunteers (mean age, $60.7 \pm 8.1$ years; 4 women) were included (Table). The stenosed vessels for patients with ICAD were as follows: unilateral intracranial ICA $(n=7)$ with stenosis locations in the cavernous $(n=5 / 7)$ and petrous $(n=2 / 7)$ segments, unilateral MCA $(n=9)$, and the basilar artery (BA, $n=6)$. The study was conducted in accordance with a protocol approved by the local institutional review board, which permitted retrospective chart review. Informed consent was obtained from all healthy volunteers.

\section{MR Imaging}

All measurements were performed on a $1.5 \mathrm{~T}$ or 3T MR imaging scanner (Magnetom Avanto or Skyra; Siemens, Erlangen, Germany). 4D flow MR imaging was performed after standard T1MPRAGE and 3D TOF-MRA sequences. Cerebral 3D blood flow

Demographics and clinical features of the 22 patients with ICAD and 10 age-appropriate healthy volunteers included in the study ${ }^{a}$

\begin{tabular}{|c|c|c|c|}
\hline & \multicolumn{2}{|c|}{ Subject Groups } & \multirow[b]{2}{*}{$\begin{array}{c}P \\
\text { Values }\end{array}$} \\
\hline & $\begin{array}{c}\text { Healthy } \\
\text { Volunteers }\end{array}$ & $\begin{array}{c}\text { Patients } \\
\text { with ICAD }\end{array}$ & \\
\hline \multicolumn{4}{|l|}{ Subject characteristics } \\
\hline No. & 10 & 22 & - \\
\hline Age (yr) & $60.7 \pm 8.1$ & $68.4 \pm 14.2$ & .124 \\
\hline Sex (male/female) & $6: 4$ & $12: 10$ & - \\
\hline Height (m) & $1.74 \pm 0.12$ & $1.71 \pm 0.11$ & .503 \\
\hline Weight (kg) & $79.8 \pm 13.7$ & $76.0 \pm 14.8$ & .557 \\
\hline Body mass index $\left(\mathrm{kg} / \mathrm{m}^{2}\right)$ & $26.2 \pm 2.9$ & $26.0 \pm 3.9$ & .878 \\
\hline \multicolumn{4}{|l|}{ Stenosed vessels } \\
\hline ICA (moderate/severe) & - & $7(4 / 3)$ & - \\
\hline MCA (moderate/severe) & - & $9(3 / 6)$ & - \\
\hline BA (moderate/severe) & - & $6(2 / 4)$ & - \\
\hline
\end{tabular}

Note:- - indicates not applicable.

a "Moderate" and "severe" indicate stenosis of 50\%-70\% and $>70 \%$, respectively. $P$ values are calculated using the Mann-Whitney $U$ test; $P<.05$ was considered statistically significant.

\section{T1-MPRAGE}



3D PC-MRA

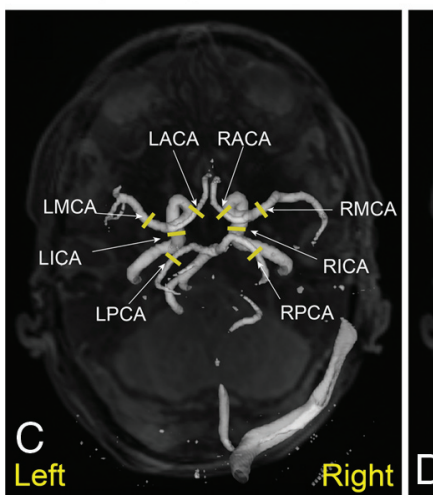

FIG 1. Sagittal T1-weighted MPRAGE $(A)$ and vessel MIP $(B)$ images of the head show the $3 D$ volume coverage for $4 D$ flow imaging. $A 3 D$ phase-contrast MR angiogram was derived from the 4D flow data and was used for positioning $2 \mathrm{D}$ analysis planes in the major cerebral arteries (C). Time-integrated 3D pathlines illustrate the cumulative flow path of the vessels within the 3D PC-MRA volume over 1 cardiac cycle $(D)$. $L$ indicates left; $R$, right.

was measured by using 4D flow MR imaging with 3-directional velocity-encoding and $3 \mathrm{D}$ volumetric coverage of the major intracranial vessels (see Fig 1 for the volume coverage). The scan was prospectively gated with electrocardiography $\mathrm{R}$ waves produced by chest leads. Pulse sequence parameters were as follows: TR = $5.4 \mathrm{~ms}$, TE $=2.8 \mathrm{~ms}$, flip angle $=15^{\circ}$, velocity sensitivity (velocityencoding $[$ VENC] $)=100 \mathrm{~cm} / \mathrm{s}$, FOV $=220 \times 160 \mathrm{~mm}^{2}$, band- 
width $=445 \mathrm{~Hz} /$ pixel, temporal resolution $=43 \mathrm{~ms}$, voxel size $=$ $(1.1-1.2) \times(1.1-1.2) \times(1.2-1.4) \mathrm{mm}^{3}$, acceleration factor $\mathrm{R}=2$ (generalized autocalibrating partially parallel acquisition), acquisition time $=15-20$ minutes depending on the heart rate of the subjects.

\section{D Blood Flow Visualization}

All 4D flow MR imaging data were preprocessed by using an inhouse software programmed in Matlab (MathWorks, Natick, Massachusetts), as previously described. ${ }^{21}$ The preprocessing included random noise reduction as well as corrections for velocity aliasing and phase offsets from Maxwell cross-terms and eddy currents. In addition, a 3D phase-contrast MR angiogram (PCMRA) was derived from the magnitude and phase-difference data (Fig 1C). The preprocessed data were then further analyzed in a $3 \mathrm{D}$ visualization software package (EnSight; CEI, Apex, North Carolina). Cerebral 3D blood flow was visualized by using timeintegrated 3D pathlines, which illustrated the collective pathline traces of 25,000 virtual particles equally distributed within the 3D PC-MRA over 1 cardiac cycle (Fig 1D). The color coding of the pathlines reflects the magnitude of blood flow velocities in the vasculature. For display purposes, a velocity window of $0-50 \mathrm{~cm} / \mathrm{s}$ was used to better visualize the flow patterns in the low-velocity vascular territories (eg, poststenosis, posterior circulation, and so forth).

\section{Vascular Flow Quantification}

As illustrated in Fig 1C, for normal cerebral vessels (ie, all vessels of healthy volunteers and those vessels without stenosis in patients), 2D analysis planes were manually positioned perpendicular to 4 prespecified pairs of cerebral arteries by using the $3 \mathrm{D}$ PC-MRA for anatomic orientation (ICA: between the lacerum C3 and cavernous C4 segments; MCA: middle M1 segment; anterior cerebral artery [ACA]: middle A1 segment; posterior cerebral artery [PCA]: middle P2 segment). For the stenosed vessel, an analysis plane was placed at approximately $1 \mathrm{~cm}$ distal to the location of the stenosis to measure poststenotic flow. For each analysis plane, volumetric flow rate (milliliter/second) and peak velocities (meter/second) were calculated. The flow analysis was performed by a scientist (C.W.) with $>7$ years of MR imaging research experience. A recent study by our group reported an excellent interobserver agreement (Lin concordance correlation coefficient, $\left.\rho_{c}=0.996\right)$ for quantitative blood flow and velocity measurements in intracranial arteries. ${ }^{12}$ The same criterion was applied for quantitative flow assessment in this study.

\section{Flow and Velocity Asymmetry Indices}

Absolute cerebral blood flow and velocity values are age- and sex-dependent. ${ }^{12,22}$ Thus, the flow/velocity ratios (asymmetry indices) between the affected (left) and nonaffected (right) arteries were used to compare the differences between patients with ICAD and healthy volunteers to minimize the impact of age and sex on flow analysis. The absolute values of the velocities and flow rates are shown in On-line Tables 1-4.

Asymmetry indices were calculated as the ratios of the flow rate (AI-F) and peak velocities (AI-V) between the affected and nonaffected side (affected/nonaffected) for patients with unilat- eral ICA and MCA stenosis or between the left and right sides (left/right) for healthy volunteers and patients with BA stenosis. In addition, schematic vascular flow models were created to characterize the normal cerebral flow distribution and stenosis-induced flow redistribution in the ipsilateral cerebral arteries compared with the contralateral counterparts.

\section{Statistical Analysis}

The asymmetry indices in each subgroup were illustrated by using box-and-whisker plots. Mann-Whitney $U$ tests were used to compare the asymmetry indices between patient subgroups and healthy volunteers. In addition, posterior-to-anterior flow ratios, the ratios of the posterior flow (PCA flow) and anterior flow (summation of ACA and MCA flow), were compared between patients with BA stenosis and healthy volunteers by using a Mann-Whitney $U$ test. All statistical analyses were performed by using the MedCalc software package (Version 14.8.1; MedCalc Software, Mariakerke, Belgium). $P<.05$ was considered statistically significant.

\section{RESULTS}

\section{Study Cohort}

Demographics and clinical features of the patients with ICAD and healthy volunteers are summarized in the Table. There were no significant differences between healthy volunteers and patients with ICAD in terms of age, height, weight, and body mass index.

\section{D Visualization of Intracranial Hemodynamics}

$3 \mathrm{D}$ flow pathlines in healthy volunteers demonstrated symmetric blood flow velocities and patterns in all prespecified cerebral arteries (Fig $2 A$, an example of the volunteers). In contrast, blood flow was compromised at the location of arterial stenosis (thick yellow arrows) compared with the contralateral counterpart (thin white arrows) in patients with unilateral ICA (Fig 2B) and unilateral MCA (Fig 2C) stenosis. Additionally, we observed elevated ipsilateral PCA flow in the patients with ICA stenosis (small pink arrow, Fig 2B) as well as increased ipsilateral ACA flow in the patients with MCA stenosis (small pink arrow, Fig 2C). Although blood flow was substantially decreased in the stenosed BA (thick yellow arrow, Fig 2D), no side-to-side flow difference was observed in a patient with BA stenosis (Fig 2D).

\section{Flow and Peak Velocity Asymmetry Indices}

For patients with ICA stenosis compared with healthy volunteers, the flow rate and peak velocity asymmetry indices (affected/nonaffected ratios) were both significantly lower in the ICA (Fig $3 A$, AI-F: $0.40 \pm 0.17$ versus $0.97 \pm 0.06, P=.001$; Fig $4 A$, AI-V: $0.57 \pm 0.16$ versus $0.95 \pm 0.09, P=.001$ ) and MCA (Fig 3B, AI-F: $0.55 \pm 0.23$ versus $0.99 \pm 0.06, P<.001 ;$ Fig $4 B, A I-V: 0.72 \pm 0.18$ versus $1.04 \pm 0.13, P=.002$ ). In contrast, the flow asymmetry index was significantly higher in the PCA (Fig 3C, AI-F: $1.55 \pm$ 0.33 versus $1.00 \pm 0.06, P<.001)$.

For patients with MCA stenosis compared with healthy volunteers, the flow and velocity asymmetry indices were both significantly lower in the ICA (Fig 3A, AI-F: $0.77 \pm 0.27$ versus $0.97 \pm$ $0.06, P=.009$; Fig $4 A$, AI-V: $0.84 \pm 0.18$ versus $0.95 \pm 0.09, P=$ .045 ) and MCA (Fig 3B, AI-F: $0.45 \pm 0.24$ versus $0.99 \pm 0.06, P<$ 

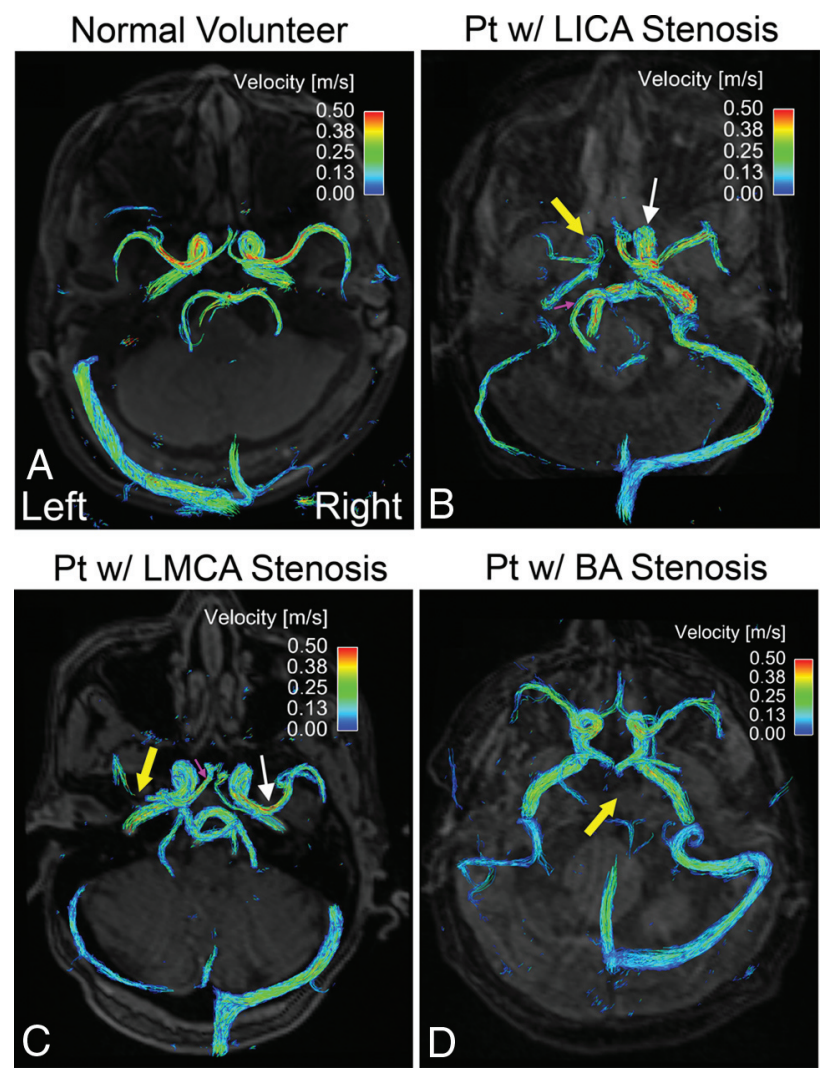

FIG 2. Time-integrated 3D pathlines illustrate symmetric and coherent flow velocities of the left and right cerebral arteries in a healthy volunteer $(A)$. Reduced blood flow velocities are observed in the stenosed vessel (thick yellow arrows) compared with the contralateral counterpart (thin white arrows) in 2 patients with left ICA (B) and left MCA (C) stenosis. The pink arrows indicate augmented ipsilateral collateral flow. In a patient with BA stenosis $(D)$, blood flow velocity is substantially decreased in the severely stenosed BA (thick yellow arrow; pathlines are invisible due to slow flow) but shows no significant side-to-side difference of flow velocities in the bilateral cerebral arteries. $\mathrm{w} /$ indicates with.

.001 ; Fig $4 B, \mathrm{AI}-\mathrm{V}: 0.68 \pm 0.27$ versus $1.04 \pm 0.13, P=.005)$. By comparison, the indices were significantly higher in the PCA (Fig $3 C$, AI-F: $1.33 \pm 0.49$ versus $1.00 \pm 0.06, P=.014$ ) and ACA (Fig $3 D$, AI-F: $1.57 \pm 0.54$ versus $1.02 \pm 0.19, P=.006$; Fig $4 D$, AI-V: $1.29 \pm 0.39$ versus $0.99 \pm 0.13, P=.042$ ).

The flow and velocity asymmetry indices were not significantly different between patients with BA stenosis and healthy volunteers in any prespecified location. However, the posterior-to-anterior flow ratios in patients with BA stenosis $(0.23 \pm 0.05)$ were significantly lower $(P=.030)$ compared with the healthy volunteers $(0.37 \pm 0.16)$.

\section{ICAD Flow-Redistribution Model}

Figure 5 illustrates the normal and stenosed schematic vascular flow models that include the 4 prespecified artery pairs. For the normal vascular model (Fig $5 A$ ), blood flow was comparable in the cerebral artery pairs. However, in the ICA stenosis model (Fig $5 B$ ), blood flow decreased in the ipsilateral ICA and MCA, but increased in the ipsilateral PCA compared with the contralateral counterparts. In the MCA stenosis model (Fig 5C), blood flow decreased in the ipsilateral ICA and MCA, but increased in the ipsilateral PCA and ACA. In contrast, there were no side-to-side flow differences in the BA stenosis model (Fig 5D).

\section{DISCUSSION}

The results of this study demonstrate the potential of $4 \mathrm{D}$ flow $\mathrm{MR}$ imaging for the comprehensive evaluation of intracranial hemodynamics in patients with ICAD. The findings demonstrate that focal intracranial atherosclerotic lesions not only alter vascular flow dynamics in the stenotic artery but also significantly influence the regional hemodynamics in other vascular territories. Indeed, unilateral intracranial atherosclerotic lesions cause cerebral blood flow redistribution across ipsilateral circle of Willis collaterals.

Catheter cerebral angiography, though invasive, remains the definitive diagnostic tool for the quantification of stenosis severity and assessment of collateral flow. Intracranial atherosclerotic lesions are dynamic and may progress or regress with time, and symptomatic ICAD involves a high recurrence rate. ${ }^{1,23}$ Thus, regular monitoring of the lesions may provide quantitative metrics of hemodynamic alternations, which may predict stroke risk and response to therapy. Noninvasive imaging modalities, such as MRA and transcranial Doppler, have high accuracy in excluding intracranial stenosis. However, these techniques may result in over- or underestimation of the stenosis due to dephasing artifacts, flow signal loss, or inadequate insonation window. ${ }^{24}$

Currently, intracranial hemodynamic disturbance in patients with ICAD is primarily assessed by sonography or quantitative MRA (2D PC-MRA). ${ }^{6,8,9,25-27}$ However, very few studies have been performed to characterize the $3 \mathrm{D}$ blood flow disturbance and flow redistribution across the major cerebral arteries in patients with ICAD. An early study by Hope et $\mathrm{al}^{28}$ reported that TOF-MRA overestimated stenosis, and 4D flow MR imaging velocity measurements could improve the accuracy of the diagnosis. Hemodynamic measurements using 3D blood flow patterns can enhance anatomic vessel imaging in that the quantitative hemodynamic information not only improves diagnosis but can potentially be used in prognosis and risk stratification.

The impact of regional atherosclerotic lesions on the flow redistribution across cerebral vessels remains incompletely understood. Using quantitative MRA, Ruland et $\mathrm{al}^{29}$ observed elevated ipsilateral PCA flow in patients with ICA or MCA stenosis. van Everdingen et $\mathrm{al}^{30}$ reported reduced ipsilateral MCA flow in patients with ICA occlusion. In our study, we found decreased ipsilateral MCA flow and increased ipsilateral PCA flow in patients with ICA or MCA stenosis, which is in agreement with the previous findings. Additionally, we identified increased ipsilateral ACA flow in patients with MCA stenosis.

Previous studies have demonstrated that the interhemispheric differences of cerebral flow parameters in healthy subjects were not significant. An early study by Sorteberg et $\mathrm{al}^{31}$ reported that there were only minor side-to-side differences of blood flow velocities in healthy adults and a difference of $>14 \%$ was considered abnormal in the ICAs and MCAs. Obata et $\mathrm{al}^{32}$ also identified no significant difference between left and right ICA flow in healthy subjects. We corroborated these findings in healthy volunteers and noted significant side-to-side flow dif- 
ICA (AI-F)



PCA (AI-F)

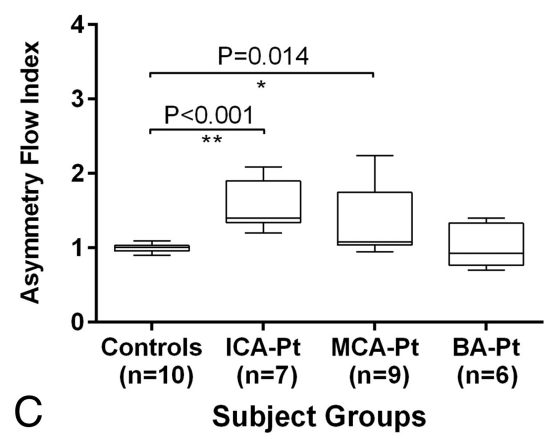

MCA (AI-F)
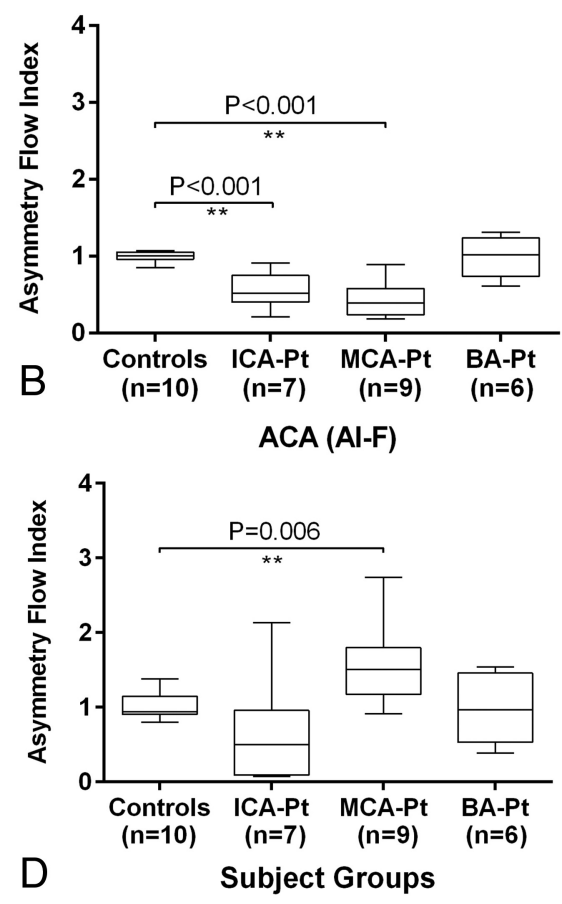

FIG 3. Asymmetry index of the blood flow in 4 major cerebral vessel locations (A, ICA; $B$, MCA; $C$, PCA; and D, ACA $)$ in patients with stenosis in the ICA $(n=7)$, MCA $(n=9)$, and BA $(n=6)$ compared with age-appropriate healthy volunteers $(n=10)$. Single and double asterisks indicate significant differences with $.01 \leq P<.05$ and $P<.01$, respectively. ICA-Pt, MCA-Pt, and BA-Pt are patients with ICA, MCA, and BA stenosis, respectively.

ICA (AI-V)

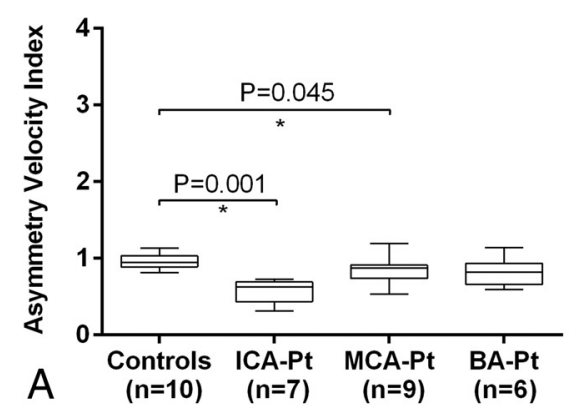

PCA (AI-V)

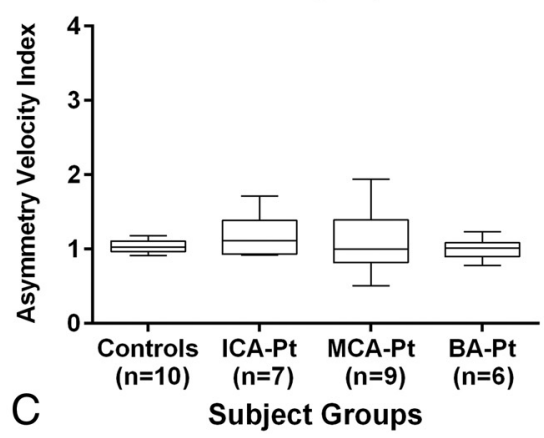

MCA (AI-V)
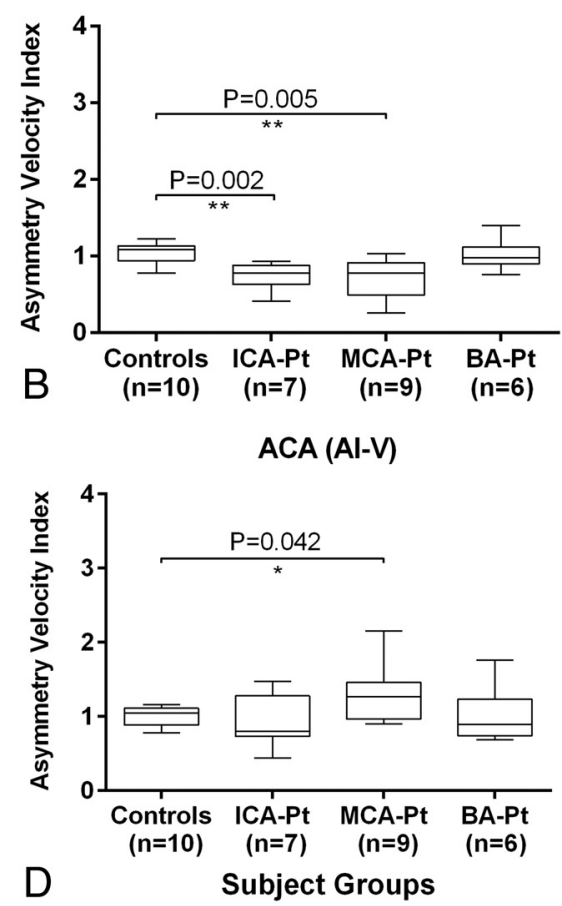

FIG 4. Asymmetry index of the peak velocities in 4 major cerebral vessel locations ( $A, I C A ; B$, MCA; C, PCA; and D, ACA) in patients with stenosis in the ICA $(n=7), \operatorname{MCA}(n=9)$, and BA $(n=$ 6) compared with age-appropriate healthy volunteers $(n=10)$. Single and double asterisks indicate significant differences with $.01 \leq P<.05$ and $P<.01$, respectively. ICA-Pt, MCA-Pt, and BA-Pt are patients with ICA, MCA, and BA stenosis, respectively.

ferences in symptomatic patients with unilateral ICA or MCA stenosis, consistent with prior observations. ${ }^{29,30,33}$

Collateral flow has been recognized as an independent predictor of recurrent stroke risk in patients with symptomatic intracranial atherosclerosis. ${ }^{34}$ In patients with unilateral ICA stenosis, we observed significantly decreased flow in the ipsilateral ICA and MCA but increased flow in the ipsilateral PCA, indicating possible PCA-to-MCA collateral flow pathways to maintain necessary perfusion pressure in the MCA territory. The finding is consistent with previous studies that reported higher blood flow or velocities in the ipsilateral PCA in patients with ICA lesions. ${ }^{29,35}$ Similarly, in patients with unilateral MCA stenosis, we identified significantly decreased flow in the ipsilateral ICA and MCA but increased flow in the ipsilateral ACA and PCA, suggesting potential ACA-toMCA and PCA-to-MCA collateral flow pathways via leptomeningeal anastomoses. ${ }^{36}$ The finding also agrees with previous reports that have shown elevated flow or velocities in the ipsilateral ACA and PCA in patients with MCA stenosis or occlusion. ${ }^{37,38}$ In contrast, no sideto-side differences of the flow parameters were observed in patients with BA stenosis, indicating no interhemispheric difference of BA flow distribution. However, significantly lower posterior-toanterior flow ratios in patients with BA stenosis compared with healthy volunteers indicate hemodynamic compromise in the posterior circulation.

For image acquisition, $1.5 \mathrm{~T}$ and $3 \mathrm{~T}$ MR imaging scanners were used, depending on the availability of the scanners. However, previous studies have shown that the influence of different field strengths on quantitative blood flow assessment was minor. ${ }^{10,39}$ Quantitative flow measurements in intracranial vessels and the thoracic aorta were not significantly different between $1.5 \mathrm{~T}$ and $3 \mathrm{~T}$.

\section{Limitations}

The small number of patients in each stenosis subgroup is a major limitation of the study, which precludes a systematic analysis of the association between stenosis severity and quantitative flow parameters and the influence of differ- 

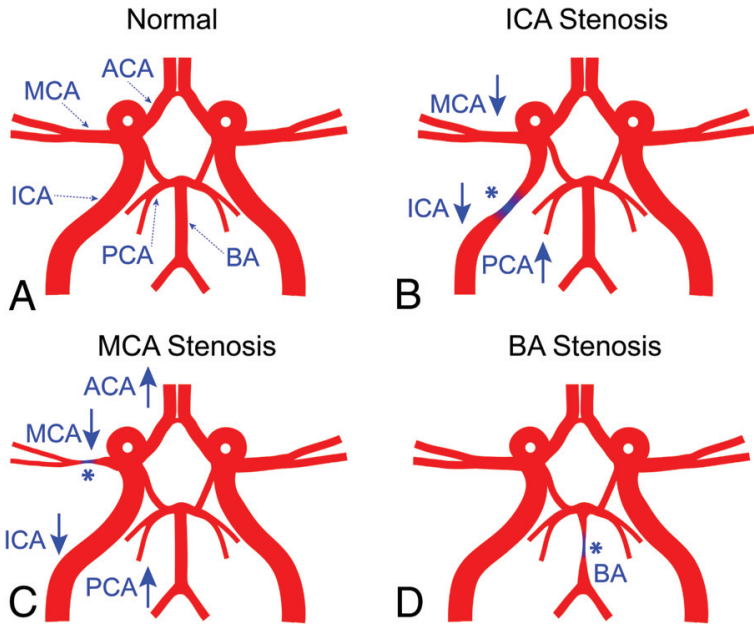

FIG 5. Schematic cerebral vascular models ( $A$, normal; $B$, ICA stenosis; $C, M C A$ stenosis; and $D, B A$ stenosis) illustrate the impact of regional stenotic lesions on blood flow in other cerebral vascular territories. The asterisk represents the location of the stenosis. The up arrow and down arrow indicate a relative increase or decrease of flow in the local vessel compared with the contralateral counterpart in patients with intracranial atherosclerosis.

ent vascular variants of the circle of Willis (eg, ACA or PCA hypoplasia) and intracranial atherosclerotic risk factors (eg, diabetes, hypertension, hypercholesterolemia, and so forth) on cerebral hemodynamics. The flow analysis was restricted to patients with moderate and severe stenosis because greater hemodynamic alterations are expected in this group of patients compared with patients with mild stenosis. In addition, dominant ACA and PCA flow and potential blood flow redistribution across the ipsilateral circle of Willis collaterals (ie, through anterior/posterior communicating arteries) might be confounding factors to the collateral flow analysis. Further studies with larger patient cohorts, including those with mild stenosis, are warranted to investigate the impact of different vascular morphology, stenosis severity, and atherosclerosis risk factors on intracranial hemodynamic changes. Nevertheless, to our knowledge, this is the largest cohort to date for $3 \mathrm{D}$ blood flow visualization of stenosis-induced intracranial flow redistribution as well as a quantitative comparison of flow and velocity asymmetry in the major cerebral arteries between patients with ICAD and healthy volunteers.

The current $4 \mathrm{D}$ flow MR imaging technique is also limited by insufficient spatial resolution for the characterization of blood flow at sites of critical or severe stenosis. Instead, poststenotic flow was used to represent the regional flow in the stenotic artery. The in-plane resolution of $1.1-1.2 \mathrm{~mm}$ in this study was appropriate for measuring blood flow in the large cerebral arteries (eg, ICAs and MCAs). However, the accuracy of flow quantification in the smaller arteries (eg, ACAs and PCAs) may be compromised by partial volume effects. In addition, flow measurements in the posterior communicating artery and leptomeningeal collaterals are not possible. Therefore, a higher magnetic field (7T) with increased spatial resolution may be required for improved flow assessment in the smaller vessels.

The wide use of $4 \mathrm{D}$ flow $\mathrm{MR}$ imaging in clinical applications is hindered by its relatively long scanning time. Noticeable effort has been made to accelerate data acquisition by using non-Cartesian sampling or compressed sensing techniques. For example, the phase contrast with vastly undersampled isotropic projection re- construction sequence based on a highly undersampled 3D radial acquisition enables a total imaging time of $<8$ minutes. ${ }^{40}$ Basha et $\mathrm{al}^{41}$ reported an acceleration factor of 7 by using randomly undersampled echo-planar imaging with compressed sensing reconstruction. A recent study by Dyvorne et $\mathrm{al}^{42}$ has demonstrated the feasibility of an abdominal $4 \mathrm{D}$ flow MR imaging scan in a single breath-hold by combining spiral sampling and dynamic compressed sensing. In addition, the limited availability of the $4 \mathrm{D}$ flow MR imaging sequence further hinders its wide implementation in clinical sites.

In addition, single-VENC $4 \mathrm{D}$ flow $\mathrm{MR}$ imaging includes an inherent trade-off related to the selection of an optimal VENC. On the one hand, the VENC should be higher than the maximum expected velocity to avoid velocity aliasing. On the other hand, a VENC that is too high undermines the reliability for detecting slow flow (eg, reduced flow in the stenosed vessels) because the velocity noise level is proportional to the VENC. Dual- or multiVENC techniques have been proposed to extend the dynamic range of velocities that can be reliability assessed. ${ }^{43,44}$ Complex flow characteristics (eg, disturbed or turbulent flow fluctuations associated with vascular stenosis) cause flow-related signal loss and present another challenge for accurate poststenotic flow assessment. Ultrashort TE 4D flow MR imaging has been shown to provide more reliable stenotic flow quantification. ${ }^{45,46} \mathrm{~A}$ recent study by Petersson et $\mathrm{al}^{47}$ reported a stack-of-spiral technique, which provided more favorable stenotic flow assessment against the conventional Cartesian counterpart.

\section{CONCLUSIONS}

The study demonstrates the potential of $4 \mathrm{D}$ flow $\mathrm{MR}$ imaging for comprehensive hemodynamic characterization in patients with intracranial atherosclerosis. The results indicate that regional atherosclerotic lesions can not only alter local vascular flow dynamics but also significantly influence the hemodynamics in other vascular territories, potentially due to collateral flow recruitment. 4D flow MR imaging provides additional hemodynamic information that may assist in elucidating the pathophysiology and autoregulation mechanism in intracranial atherosclerosis and in predicting the risk of recurrent stroke.

Disclosures: Can Wu—RELATED: Grant: American Heart Association, Comments: American Heart Association Predoctoral Fellowship 14PRE18370014.* Sameer Ansari-UNRELATED: Grants/Grants Pending: Radiological Society of North America, American Heart Association, and National Institutes of Health grants. * James CarrUNRELATED: Board Membership: Bayer AG, Comments: Advisory Board; Grants/ Grants Pending: Bayer AG, Siemens.* Shyam Prabhakaran-UNRELATED: Grants/ Grants Pending: National Institute of Neurological Disorders and Stroke, PatientCentered Outcomes Research Institute*; Royalties: UpToDate. *Money paid to the institution.

\section{REFERENCES}

1. Arenillas JF. Intracranial atherosclerosis: current concepts. Stroke 2011;42:S20-23 CrossRef Medline

2. Jeng JS, Tang SC, Liu HM. Epidemiology, diagnosis and management of intracranial atherosclerotic disease. Expert Rev Cardiovasc Ther 2010;8:1423-32 CrossRef Medline

3. Chimowitz MI, Lynn MJ, Derdeyn CP, et al; SAMMPRIS Trial Investigators. Stenting versus aggressive medical therapy for intracranial arterial stenosis. N Engl J Med 2011;365:993-1003 CrossRef Medline

4. Prabhakaran S, Warrior L, Wells KR, et al. The utility of quantitative magnetic resonance angiography in the assessment of intracranial in-stent stenosis. Stroke 2009;40:991-93 CrossRef Medline 
5. Prabhakaran S, Wells KR, Jhaveri MD, et al. Hemodynamic changes following Wingspan stent placement-a quantitative magnetic resonance angiography study. J Neuroimaging 2011;21:e109-13 CrossRef Medline

6. Amin-Hanjani S, Alaraj A, Calderon-Arnulphi M, et al. Detection of intracranial in-stent restenosis using quantitative magnetic resonance angiography. Stroke 2010;41:2534-38 CrossRef Medline

7. Amin-Hanjani S, Rose-Finnell L, Richardson D, et al; VERiTAS Study Group. Vertebrobasilar Flow Evaluation and Risk of Transient Ischaemic Attack and Stroke study (VERiTAS): rationale and design. Int J Stroke 2010;5:499-505 CrossRef Medline

8. Baumgartner RW, Mattle HP, Schroth G. Assessment of $\geq \mathbf{5 0} \%$ and $<50 \%$ intracranial stenoses by transcranial color-coded duplex sonography. Stroke 1999;30:87-92 CrossRef Medline

9. Wang L, Xing Y, Li Y, et al. Evaluation of flow velocity in unilateral middle cerebral artery stenosis by transcranial Doppler. Cell Biochem Biophys 2014;70:823-30 CrossRef Medline

10. Bammer R, Hope TA, Aksoy M, et al. Time-resolved 3D quantitative flow MRI of the major intracranial vessels: initial experience and comparative evaluation at $1.5 \mathrm{~T}$ and $3.0 \mathrm{~T}$ in combination with parallel imaging. Magn Reson Med 2007;57:127-40 CrossRef Medline

11. Markl M, Frydrychowicz A, Kozerke S, et al. 4D flow MRI. J Magn Reson Imaging 2012;36:1015-36 CrossRef Medline

12. Wu C, Honarmand AR, Schnell S, et al. Age-related changes of normal cerebral and cardiac blood flow in children and adults aged 7 months to 61 years. J Am Heart 2016;5:pii: e002657 CrossRef Medline

13. Ansari SA, Schnell S, Carroll T, et al. Intracranial 4D flow MRI: toward individualized assessment of arteriovenous malformation hemodynamics and treatment-induced changes. AJNR Am J Neuroradiol 2013;34:1922-28 CrossRef Medline

14. Schnell S, Ansari SA, Vakil P, et al. Three-dimensional hemodynamics in intracranial aneurysms: influence of size and morphology. $J$ Magn Reson Imaging 2014;39:120-31 CrossRef Medline

15. Wu C, Ansari SA, Honarmand AR, et al. Evaluation of 4D vascular flow and tissue perfusion in cerebral arteriovenous malformations: influence of Spetzler-Martin grade, clinical presentation, and AVM risk factors. AJNR Am J Neuroradiol 2015;36:1142-49 CrossRef Medline

16. Wu C, Schnell S, Markl M, et al. Combined DSA and 4D flow demonstrate overt alterations of vascular geometry and hemodynamics in an unusually complex cerebral AVM. Clin Neuroradiol 2015 Oct 16. [Epub ahead of print] CrossRef Medline

17. Wu C, Schoeneman SE, Kuhn R, et al. Complex alterations of intracranial 4D hemodynamics in vein of Galen aneurysmal malformations during staged endovascular embolization. Operative Neurosurg 2016;12:239-49 CrossRef

18. Nguyen-Huynh MN, Wintermark M, English J, et al. How accurate is CT angiography in evaluating intracranial atherosclerotic disease? Stroke 2008;39:1184-88 CrossRef Medline

19. Choi CG, Lee DH, Lee JH, et al. Detection of intracranial atherosclerotic steno-occlusive disease with $3 \mathrm{D}$ time-of-flight magnetic resonance angiography with sensitivity encoding at 3T. AJNR Am J Neuroradiol 2007;28:439-46 Medline

20. Debrey SM, Yu H, Lynch JK, et al. Diagnostic accuracy of magnetic resonance angiography for internal carotid artery disease: a systematic review and meta-analysis. Stroke 2008;39:2237-48 CrossRef Medline

21. Bock J, Kreher BW, Hennig J, et al. Optimized pre-processing of time-resolved 2D and 3D phase contrast MRI data. In: Proceedings of the Scientific Meeting and Exhibition of the International Society for Magnetic Resonance in Medicine, Berlin, Germany. May 19-25, 2007:3138

22. Bakker SL, de Leeuw FE, den Heijer T, et al. Cerebral haemodynamics in the elderly: the Rotterdam Study. Neuroepidemiology 2004;23: 178-84 CrossRef Medline

23. Akins PT, Pilgram TK, Cross DT 3rd, et al. Natural history of stenosis from intracranial atherosclerosis by serial angiography. Stroke 1998;29:433-38 CrossRef Medline
24. Khan M, Naqvi I, Bansari A, et al. Intracranial atherosclerotic disease. Stroke Res Treat 2011;2011:282845 CrossRef Medline

25. Amin-Hanjani S, Du XJ, Zhao MD, et al. Use of quantitative magnetic resonance angiography to stratify stroke risk in symptomatic vertebrobasilar disease. Stroke 2005;36:1140-45 CrossRef Medline

26. Mizuma A, Ishikawa T, Kajihara N, et al. Dynamic cross-sectional changes of the middle cerebral artery in atherosclerotic stenosis detected by 3.0-Tesla MRI. Neurol Res 2014;36:795-99 CrossRef Medline

27. Zhao L, Barlinn K, Sharma VK, et al. Velocity criteria for intracranial stenosis revisited: an international multicenter study of transcranial Doppler and digital subtraction angiography. Stroke 2011;42: 3429-34 CrossRef Medline

28. Hope TA, Hope MD, Purcell DD, et al. Evaluation of intracranial stenoses and aneurysms with accelerated 4D flow. Magn Reson Imaging 2010;28:41-46 CrossRef Medline

29. Ruland S, Ahmed A, Thomas K, et al. Leptomeningeal collateral volume flow assessed by quantitative magnetic resonance angiography in large-vessel cerebrovascular disease. J Neuroimaging 2009; 19:27-30 CrossRef Medline

30. van Everdingen KJ, Kappelle LJ, Klijn CJ, et al. Clinical features associated with internal carotid artery occlusion do not correlate with MRA cerebropetal flow measurements. J Neurol Neurosurg Psychiatry 2001;70:333-39 CrossRef Medline

31. Sorteberg W, Langmoen IA, Lindegaard KF, et al. Side-to-side differences and day-to-day variations of transcranial Doppler parameters in normal subjects. J Ultrasound Med 1990;9:403-09 Medline

32. Obata T, Shishido F, Koga M, et al. Three-vessel study of cerebral blood flow using phase-contrast magnetic resonance imaging: effect of physical characteristics. Magn Reson Imaging 1996;14: 1143-48 CrossRef Medline

33. Brint SU, Al-Khalidi HR, Vatel B, et al. MCA flow asymmetry is a marker for cerebrovascular disease. Neurol Res 1996;18:163-67 CrossRef Medline

34. Liebeskind DS, Cotsonis GA, Saver JL, et al; Warfarin-Aspirin Symptomatic Intracranial Disease (WASID) Investigators. Collateral circulation in symptomatic intracranial atherosclerosis. J Cereb Blood Flow Metab 2011;31:1293-301 CrossRef Medline

35. Zanette EM, Fieschi C, Bozzao L, et al. Comparison of cerebral angiography and transcranial Doppler sonography in acute stroke. Stroke 1989;20:899-903 CrossRef Medline

36. Brozici M, van der Zwan A, Hillen B. Anatomy and functionality of leptomeningeal anastomoses: a review. Stroke 2003;34:2750-62 CrossRef Medline

37. Brass LM, Duterte DL, Mohr JP. Anterior cerebral artery velocity changes in disease of the middle cerebral artery stem. Stroke 1989; 20:1737-40 CrossRef Medline

38. Uemura A, O'Uchi T, Kikuchi Y, et al. Prominent laterality of the posterior cerebral artery at three-dimensional time-of-flight MR angiography in M1-segment middle cerebral artery occlusion. AJNR Am J Neuroradiol 2004;25:88-91 Medline

39. Strecker C, Harloff A, Wallis W, et al. Flow-sensitive 4D MRI of the thoracic aorta: comparison of image quality, quantitative flow, and wall parameters at $1.5 \mathrm{~T}$ and 3 T. J Magn Reson Imaging 2012;36: 1097-103 CrossRef Medline

40. Gu T, Korosec FR, Block WF, et al. PC VIPR: a high-speed 3D phasecontrast method for flow quantification and high-resolution angiography. AJNR Am J Neuroradiol 2005;26:743-49 Medline

41. Basha TA, Akçakaya M, Goddu B, et al. Accelerated three-dimensional cine phase contrast imaging using randomly undersampled echo planar imaging with compressed sensing reconstruction. NMR Biomed 2015;28:30-39 CrossRef Medline

42. Dyvorne H, Knight-Greenfield A, Jajamovich G, et al. Abdominal 4D flow MR imaging in a breath hold: combination of spiral sampling and dynamic compressed sensing for highly accelerated acquisition. Radiology 2015;275:245-54 CrossRef Medline

43. Ha H, Kim GB, Kweon J, et al. Multi-VENC acquisition of fourdimensional phase-contrast MRI to improve precision of velocity 
field measurement. Magn Reson Med 2016;75:1909-19 CrossRef Medline

44. Schnell S, Rose MJ, Wu C, et al. Improved assessment of aortic hemodynamics by $k$ - $t$ accelerated dual-VENC $4 \mathrm{D}$ flow MRI in pediatric patients. J Cardiovasc Magn Reson 2016;18(suppl):O96 CrossRef

45. Kadbi M, Negahdar M, Cha JW, et al. 4D UTE flow: a phase-contrast MRI technique for assessment and visualization of stenotic flows. Magn Reson Med 2015;73:939-50 CrossRef Medline
46. O’Brien KR, Myerson SG, Cowan BR, et al. Phase contrast ultrashort TE: a more reliable technique for measurement of high-velocity turbulent stenotic jets. Magn Reson Med 2009;62:626-36 CrossRef Medline

47. Petersson S, Dyverfeldt P, Sigfridsson A, et al. Quantification of turbulence and velocity in stenotic flow using spiral three-dimensional phase-contrast MRI. Magn Reson Med 2016;75:1249-55 CrossRef Medline 